\title{
Erratum to: A Cohort Study Predicts Better Functional Outcomes and Equivalent Patient Satisfaction Following UKR Compared with TKR
}

Douglas J. Matthews, MRCS, BSc • Fahad Siddique Hossain, MRCS • Shelain Patel, MRCS •

Fares S. Haddad, BSc, MCh(Orth), FRCS(Orth)

Erratum to: HSSJ

DOI 10.1007/s11420-012-9326-4

The name of one of the authors was spelled incorrectly. The correct spelling is Fares S. Haddad

The online version of the original article can be found at http://dx.doi.org/ $10.1007 / \mathrm{s} 11420-012-9326-4$.

D. J. Matthews, MRCS, BSc $(\bowtie) \cdot F$. S. Hossain, MRCS •

S. Patel, MRCS · F. S. Haddad, BSc, MCh(Orth), FRCS(Orth)

University College London Hospital,

235 Euston Road, London NW1 2BU, UK

e-mail: douglasmatthews@doctors.org.uk 